\section{Autoantikörper gegen Prothrombin}

\author{
W. Stöcker \\ Euroimmun Medizinische Labordiagnostika AG, Lübeck, \\ Deutschland
}

Synonym(e) aPS/PT; aPT; Prothrombin-Antikörper

Englischer Begriff anti-prothrombin antibodies

Definition Zur Gruppe der Antiphospholipid-Antikörper zählende, gegen körpereigenes Prothrombin gerichtete Autoantikörper.

Funktion - Pathophysiologie Antikörper gegen Prothrombin (aPT) wurden erstmals im Jahr 1959 als mögliche Kofaktoren des Lupus-Antikoagulans (LA) diskutiert. Prothrombin ist ein Vitamin-K-abhängiges, in den Hepatozyten gebildetes Glykoprotein mit einer Molmasse von 70 kDa und neben $\beta 2$ Glykoprotein I ( $\beta 2-\mathrm{GPI})$ und Annexin A5 eines der wichtigsten Phospholipid-bindenden Proteine. Im Verlauf der Biosynthese werden die ersten 10 N-terminalen Glutamatreste enzymatisch $\gamma$-carboxyliert. Diese $\gamma$-Carboxyglutamat-haltige Region (Gla-Domänen) vermittelt die calciumabhängige Bindung an Phosphatidylserin, die zu einer Konformationsänderung des Prothrombins führt. Die enzymatische Aktivierung des Prothrombins zu $\alpha$-Thrombin im Verlaufe einer Blutgerinnungsreaktion erfolgt durch den Prothrombinasekomplex, bestehend aus den Faktoren Va und Xa ( $>$ Gerinnungsfaktor $\mathrm{X})$ sowie Phospholipiden (s. $>$ Phospholipide) und $\triangleright \mathrm{Cal}-$ cium-Ionen.

Untersuchungsmaterial Serum, Plasma.
Probenstabilität Autoantikörper sind bei $+4{ }^{\circ} \mathrm{C}$ bis $\mathrm{zu}$ 2 Wochen lang beständig, bei $-20{ }^{\circ} \mathrm{C}$ über Monate und Jahre hinweg.

Analytik Enzyme-linked Immunosorbent Assay.

Referenzbereich - Erwachsene Nicht nachweisbar.

Referenzbereich - Kinder Nicht nachweisbar.

Interpretation Die gehäuft bei Patienten mit systemischem Lupus erythematodes (SLE) auftretenden Anti-Prothrombin-

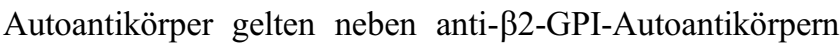
als Risikofaktoren für arterielle, nicht jedoch für venöse Thrombosen. Für aPT wurde im Tierversuch die Thromboseinduzierende Wirkung gezeigt. Eine Beteiligung an habituellen Aborten wird diskutiert.

Die Anti-Prothrombin-Autoantikörper sind heterogen. Ihre Bestimmung erfolgt im ELISA. Hierbei werden festphasengebundenes isoliertes Prothrombin (PT) oder ein Komplex aus Phosphatidylserin und Prothrombin (PS/PT) als Antigene eingesetzt.

Vergleichsstudien zeigen, dass aPS/PT im Gegensatz zu aPT sehr gut mit der klinischen Manifestation des Antiphospholipid-Syndroms (APS) korreliert und die gleiche

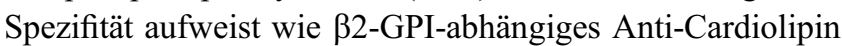
(aCL oder ACA; Autoantikörper gegen Cardiolipin) beim APS. Demnach ist aPS/PT-IgG auch mit $>$ Lupus-

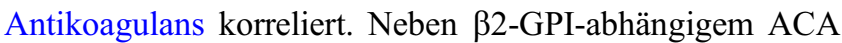
stellt aPS/PT einen sehr guten Marker für das APS dar.

\section{Literatur}

Atsumi T, Amengual O, Yasuda S et al (2004) Antiprothrombin antibodies-are they worth assaying? Thromb Res 114:533-538 